\title{
Profiling and charaterization of chemical and pathogenic cumulative stress responding genes in mouse liver
}

\author{
Farida Behlil ${ }^{*}$, Muhammad Younas Khan Barozai ${ }^{2}$, Samiullah $^{3}$, Farrukh \\ Bashir $^{1}$, Shafia Muzaffar ${ }^{1}$, Saba Afzal ${ }^{1}$ and Muzaffar Khan ${ }^{1}$ \\ 1. Department of Chemistry, Sardar Bahadur Khan Women University, Brewery Road Quetta-Pakistan \\ 2. Department of Botany, University of Baluchistan, Sariab Road Quetta-Pakistan \\ 3. Department of Chemistry, University of Baluchistan, Sariab Road Quetta-Pakistan \\ *Corresponding author's email: faridabehlil@yahoo.com
}

Citation

Farida Behlil, Muhammad Younas Khan Barozai, Samiullah, Farrukh Bashir, Shafia Muzaffar, Saba Afzal and Muzaffar Khan. Profiling and charaterization of chemical and pathogenic cumulative stress responding genes in mouse liver. Pure and Applied Biology. Vol. 5, Issue 4, pp1323-1333. http://dx.doi.org/10.19045/bspab.2016.50159

\begin{tabular}{llll}
\hline \hline Received: 24/10/2016 & Revised: 01/12/2016 & Accepted: 07/12/2016 & Online First: 10/12/2016 \\
\hline \hline
\end{tabular}

Abstract

The present study was done for the profiling and characterization of cumulative stress responding genes in mouse (Mus musculus) liver. The mouse liver responses to chemical and pathogenic stresses at transcriptome level provide an understanding for the profiling of stress responding genes. The cumulative chemical and pathogenic stress genes responding to three or more than three stress series will be a good source for genetic engineering at chemical and pathogenic stress resistance mechanism in liver. In mouse various studies have been made for the analysis of gene expression under various chemical and pathogenic stress conditions using DNA microarray technology. These available microarray data under chemical and pathogenic stresses like; aromatic compounds, perflurooctonic sulphate, arsenic and Helicobacter hepiticus were analyzed by applying the bioinformatics tools. Total 363 cumulative chemical and pathogenic stress responding genes were profiled and characterized at different stages after the analysis of 45101 genes. The chemical and pathogenic stress responding genes were characterized on the basis of their functions.

Keywords: Gene expression; Gene ontology; DNA microarray; Chemical stress; Pathogenic stress

\section{Introduction}

Mouse (Mus musculus) is one of the most unusual and commonly distributed rodents in the world [1]. Mouse is commonly used for modeling human diseases and comparisons of genome analysis. It has a vital role in the annotation of genome and studying the function and regulation of genes and an experimental model to examine the problems of the system and pathogenesis of human cancer [2], in various organs such as the kidneys [3], stomach [4], and liver [5]. In mammals liver is the second largest organ, as skin is the first. The liver supports all the organs of the body to live a healthy life. It can be classified by both the effect and the causes. Effects may include obstruction, inflammation, blood clotting abnormalities, and cancer [6]. The causes may include autoimmune process, genetic 
defects, injuries, pathogens [7] and also the exposure to toxic chemicals $[5,6,8]$.

Numbers of chemicals are found to be involved in liver cancer such as, perflurooctane sulfate (PFOS) a stable manmade chemical that has been used since 1950 in the making of variety of commercial and industrial products [5] and also profiled as a persistent organic pollutant. Its contaminations are found in bone marrow, blood, lungs and heart of laboratory rodents [9]. It changes the expression of genes that participate in inflammation, xenobiotic, and lipid metabolism in different laboratory animals [5]. Toxic metalloid arsenic (As) is a carcinogenic element that naturally occurs in environment. Arsenic exposure to human beings is associated with the use of contaminated drinking water from natural and geological sources [6]. Arsenic-induced liver pathology can be progress to fibrosis, cirrhosis and even cause cancer [10].

Pathogenic association in liver cancer has been known for more than a century and different types of parasites, viruses and bacteria have been associated with oncongenic process. One such pathogen is Helicobacter hepaticus, which was first isolated from rat liver tissue, causes inflammation of the gastrointestinal tract and the risk of liver cancer in human beings as well as in different strains of mice [11].

DNA microarrays, a well know gene expression technology have been extensively used in the analysis of expression of genes in mice and various studies have been developed for the analysis of gene expression under chemical and pathogenic stress conditions using cDNA microarray technology $[\mathbf{8}, \mathbf{1 0}]$. Profiling and characterization of genes in different organisms under various stresses gained importance due to the increase in the database [12]. In this research cumulative chemical and pathogenic stress responding genes in mouse liver have been profiled by using different tools of bioinformatics and gene expression databases such as Gene Expression Omnibus (GEO) [13] and Gene Ontology (GO) [14]. The multi experimental viewer (MeV) microarray tool [16] was applied for the analysis of data through graphical visualization. A total of 363 cumulative chemical and pathogenic stresses responding genes, including 224 upregulated and 139 down-regulated genes were profiled and characterized at different stages. The profiled genes were further characterized according to their cellular components, molecular functions and biological processes through Gene Ontology (GO).

\section{Materials and methods}

\section{Microarray data mining}

This analysis is based on the comparative analysis of microarray data by using various bioinformatics tools and gene expression database such as; Gene Expression Omnibus (GEO) [13] and Gene Ontology (GO) [14] etc. For such kind of studies, it is obligatory to use uniformed platform for which a number of series and samples should be available. To meet this criteria first step is the microarray data mining. Mouse is one of the major mammals and liver is the vital internal organ whose extensive microarray data is publically available at GEO-NCBI (www.ncbi.nlm.nih.gov/geo). Total 101 platforms, 2399 series and 30528 samples were found for mouse liver microarray data. All of these entire mouse liver microarrays were mined for chemical and pathogenic stresses. Finally GPL1261 with four series (GSE5128, GSE22871, GSE9630 and GES9097) were selected for the comparative analysis. These series contain 45101 genes. All the relevant data belonging to these series were downloaded and saved.

\section{Experimental design}

The experimental design is a very pivotal step for microarray data analysis. So, for the current study an inclusive but brief and 
logical experimental design was formed, to attain the greatest set of chemical and pathogenic stress responding genes. All the data was clustered into five stages on the basis of their doses. These stages were Low Minimum (LD-Min), Low Maximum (LDMax), High Minimum (HD-Min), High Maximum (HD-Max) and Cumulative.

In low dose minimum stress the data for stress was $\mathrm{N}$-(1-napththyl) ethylenediamine dihydrochloride (NEDD) for aromatic compounds, $3 \mathrm{mg} / \mathrm{kg}$ for PFOS, 10ppb as food and water sodium arsenite for arsenic, hep for Helicobacter hepiticus. In low dose maximum stress the data for stress was pentachloronitrobenzene (PCNB) for aromatic compounds, $3 \mathrm{mg} / \mathrm{kg}$ for PFOS, $100 \mathrm{ppb}$ sodium arsenite as drinking water for arsenic, hep for Helicobacter hepiticus. In high dose minimum stress the data for stress was 1,5-Naphthalenediamine (NAPD) for aromatic compounds, $10 \mathrm{mg} / \mathrm{kg}$ for PFOS, $1 \mathrm{mg} / \mathrm{kg}$ sodium arsenite with $1 \mathrm{mg} / \mathrm{kg}$ dexamethasone for sodium arsenite, tumor for Helicobacter hepiticus. In high dose maximum stress, the data for stress was 2,3benzofuran (BFUR) for aromatic compounds, $10 \mathrm{mg} / \mathrm{kg}$ for PFOS, $1 \mathrm{mg} / \mathrm{kg}$ sodium arsenite with $1 \mathrm{~g} / \mathrm{kg}$ of dexamethasone, tumor for Helicobacter hepiticus. In cumulative low and high dose stress average values of GSE5128, GSE22871, GSE9630, and GSE9097 were taken from the samples of low and high doses. Three replicates were generated for each of sub-stress to gain the accurate result.

\section{Creation of tab-delimited aligned data} Excel sheet was generated for the platform Sopt identifiers (IDs). For the IDs, the normalized $\log _{2}$ intensities defined by robust multichip average (RMA) Expression value under chemical (aromatic compounds, PFOS, arsenic) and pathogenic (Helicobacter hepiticus) stresses were entered and aligned. Separate excel sheets were generated for five stress stages (Low-
Min, Low-Max, High-Min, High-Max, Cumulative) and each of their replicates. Then these aligned platform IDs and their $\log _{2}$ intensities values were saved as tabdelimited files [11].

\section{Gene expression data analysis}

The tab-delimited aligned data was analyzed by using multi experimental viewer $(\mathrm{MeV})$ microarray tool, for the analysis of large scale bioinformatics applications [15], publically available at (www.tm4.org/mev). $\mathrm{MeV}$ is software that has an application designed to allow the user to analyze differentially expressed genes and the microarray data to recognize different samples of gene expression [16]. JavaScript was use for the working of $\mathrm{MeV}$ software. The aligned tab-delimited data was load in multiple array viewer windows.

\section{Profiling of cumulative responding genes}

The genes responding under at-least three stresses among aromatic compounds, perflurooctonic sulphate, arsenic and Helicobacter hepiticus; showing $\log _{2}$ intensities $\geq \mid \leq 2.0$-fold were profiled as cumulative chemical and pathogenic stress responding genes and saved.

\section{Characterization studies}

For characterization annotation table of Gpl1261, is publically available at GEONCBI(www.ncbi.nlm.gov/geo/query/acc.cgi ?acc=GPL1261), was downloaded. The gene locus was subjected to Gene Ontology (GO) functional categorized on the basis of cellular components, molecular functions and biological processes. The Gene Ontology describe three demesne (cellular components, molecular functions and biological processes) of gene using organized classification and it is structured as a directed acyclic graph (DAG), and each term has definite links to one or more than one terms in the same demesne [14]. The gene annotation were characterized and saved. The number of chromosome was founded using UCSC genome browser 
(http://genome.ucsc.edu) for mouse genome and saved.

\section{Results and discussions}

\section{Cumulative chemical and pathogenic} stress responding genes

The computational analysis research through bioinformatic tools is coherent approach to find interesting findings $[12,17]$. Through another similar attempt, the mouse microarray data mining, profiling and analysis have resulted 363 cumulative chemical and pathogenic stress responding genes after analysis of 45101 genes from GPL1261 at different stress doses, Low Dose Minimum (LD-Min), Low Dose Maximum (LD-Max), High dose Minimum (HD-Min), High dose Maximum (HD-Max) and Cumulative Low and High dose (CLH). The 363 cumulative chemical and pathogenic stress responding genes have shown $\log _{2}$ signal intensities $\geq / \leq 2.0$ fold under at-least three stresses among aromatic compounds, perflurooctonic sulphate (PFOS), arsenic, and Helicobacter hepiticus. For the cumulative chemical and pathogenic stress responding genes an average intensity values were created from the genes. From 363 genes, $224(61.71 \%)$ genes (Figure 1a) showed up-regulation and 139 (38.29\%) genes (Figure 1b) showed down regulation. Similar work was reported for intervention of cervical cancer and RNA [17], and gastric cancer [11], using computational techniques.
The computational technique leads to a better understanding of animal biology and of the pathogenesis of diseases by profiling genes [17].

\section{Responding genes and stress doses}

The cumulative analysis of profiled cumulative chemical and pathogenic stress responding genes at different stress doses showed a regular increased with continuation of treatment (Figure 2). Most of the genes were observed as up-regulated $(61.71 \%)$ than down-regulated $(38.29 \%)$ at LD-Min, LD-Max, HD-Min, HD-Max and Cumulative stresses. These results showed that most of the genes increased their expression. Different researchers have studied the cumulative chemicals and pathogenic effect on different strains of mice and liver of rats $[18,19]$. The cumulative effects of chemicals and pathogen have great effect than of the individual chemicals and pathogens.

\section{Characterization studies}

The profiled cumulative chemical and pathogenic stress responding genes were categorized on the basis of cellular components, molecular function and biological processes through Gene Ontology (GO) annotation. The chromosome numbers were characterized through UCSC genome browser. 
Pure Appl. Biol., 5(4): 1323-1333, December, 2016

http://dx.doi.org/10.19045/bspab.2016.50159
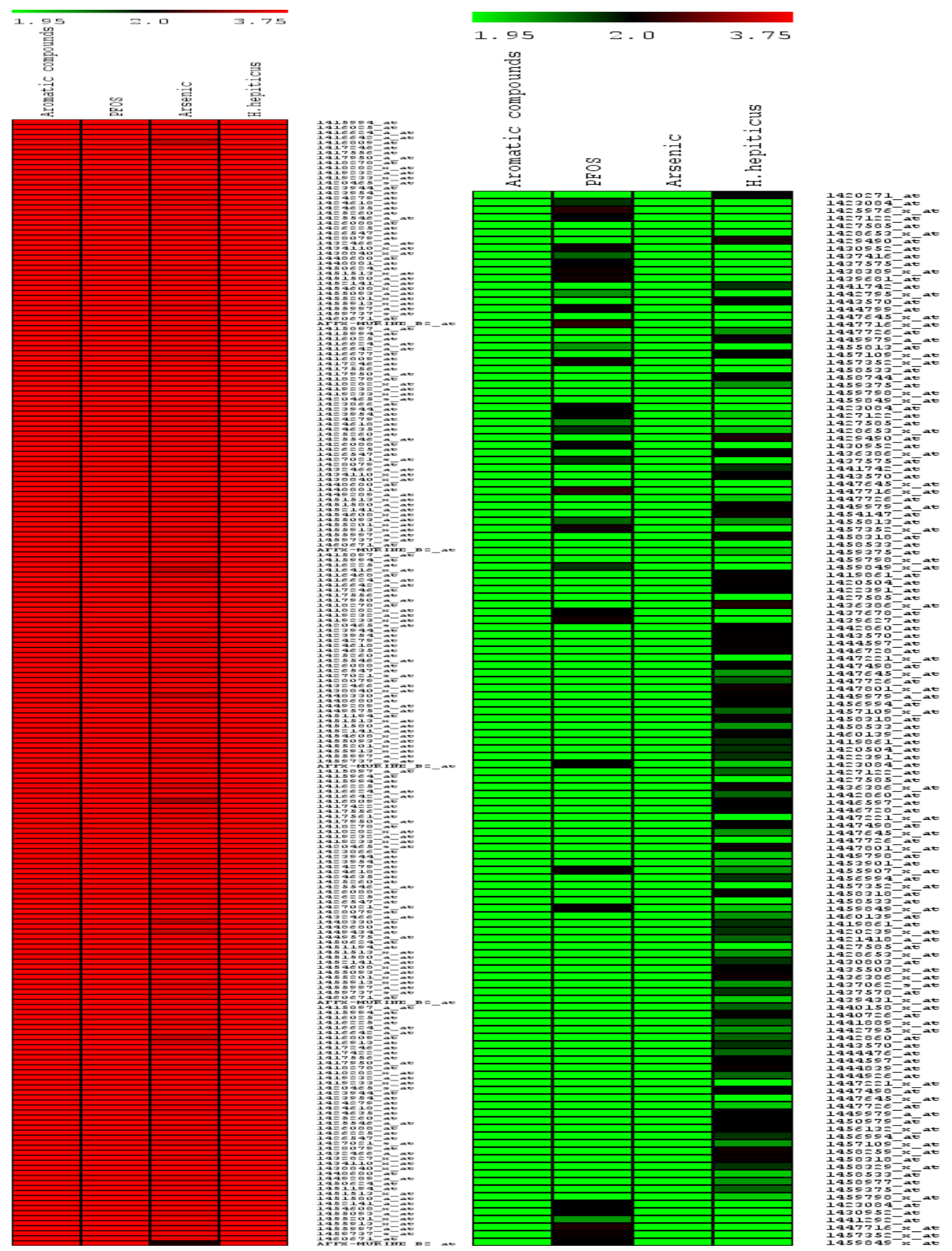

Figure 1. MEV analysis of cumulative chemical and pathogenic stress responding genes for upregulated (a-left) and down-regulated (b-right) expressions under at least three stress conditions among aromatic compounds, perflurooctanoic sulphate, arsenic (as chemical stress), and Helicobacter hepiticus (as pathogenic stress) stress 
Behlil et al.

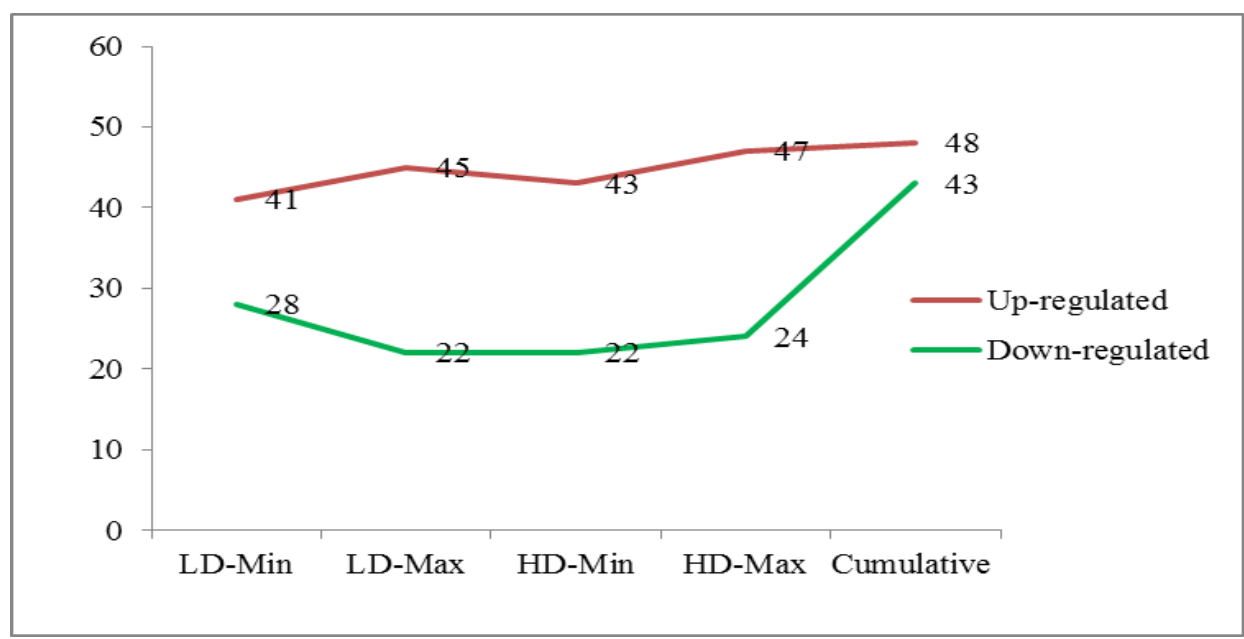

Figure 2. The comparative analysis of profiled Cumulative Chemical Pathogenic Stress Responding genes at different stress doses

Characterization for cellular components

The GO characterization for cellular components showed that $39.94 \%$ upregulated and $2.38 \%$ down regulated genes were engaged in extracellular. The $20.93 \%$ up-regulated and $7.43 \%$ down regulated genes were involved in cytoplasm. Membranes were having $15.70 \%$ upregulated and $8.53 \%$ down-regulated genes. The $20.11 \%$ up-regulated and $1.92 \%$ down regulated genes were showing protein complex. The $13.49 \%$ up-regulated and $8 \%$ down-regulated genes were involved in nucleus component. The $5.50 \%$ up-regulated and $15.70 \%$ down regulated genes components were unknown. The miscellaneous components had been shown by $12.94 \%$ up-regulated and $6.06 \%$ down regulated genes. The $8.26 \%$ up-regulated and $1.92 \%$ down-regulated genes were engaged in mitochondria (Figure 3a). The cellular components through GO annotation were involved in membrane, nucleus, cytoplasm and mitochondria almost similar components was also reported by Hazbun et al, in the analysis of assigning function to Saccharomyces cerevisiae (yeast) [20].

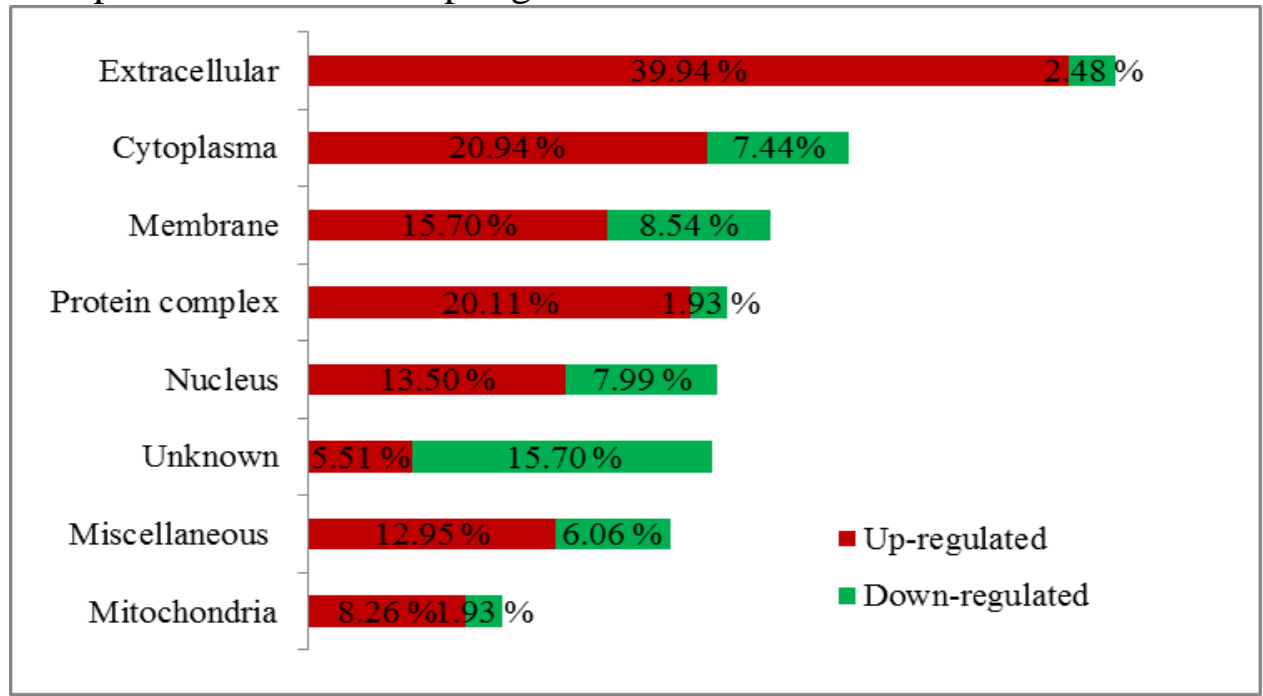

Figure 3a.The mouse liver cumulative chemical and pathogenic stress responding genes charaterization by Gene Ontology studies according to Cellular components 


\section{Characterization for molecular function}

The GO functional characterization of cumulative chemical and pathogenic stress responding genes for molecular functions showed that $50.94 \%$ up regulated and $12.12 \%$ down-regulated were involve in binding activity. The $24.51 \%$ up- regulated and $3.8 \%$ down-regulated genes were engaged in transport activity. The $19.28 \%$ up- regulated and $3.3 \%$ down-regulated genes were showing regulatory activity. The $18.18 \%$ up-regulated and $6.06 \%$ downregulated genes were engaged in catalytic activity. The $3.03 \%$ up-regulated and $17 \%$ down-regulated genes were performing unknown function. The 3\% up-regulated and $0.55 \%$ genes were showing miscellaneous molecular activity (Figure 3b). The results for molecular functions through $\mathrm{GO}$ annotation were involved in binding activity, catalytic activity, transporter activity, and regulatory activity. Thomas et al, reported the same molecular functions in analysis of mouse lungs under chemical stress [8]. Similar functional categories were almost same as that have been reported by Cox et al, analyzing the gene expression of liver of baboons[21].

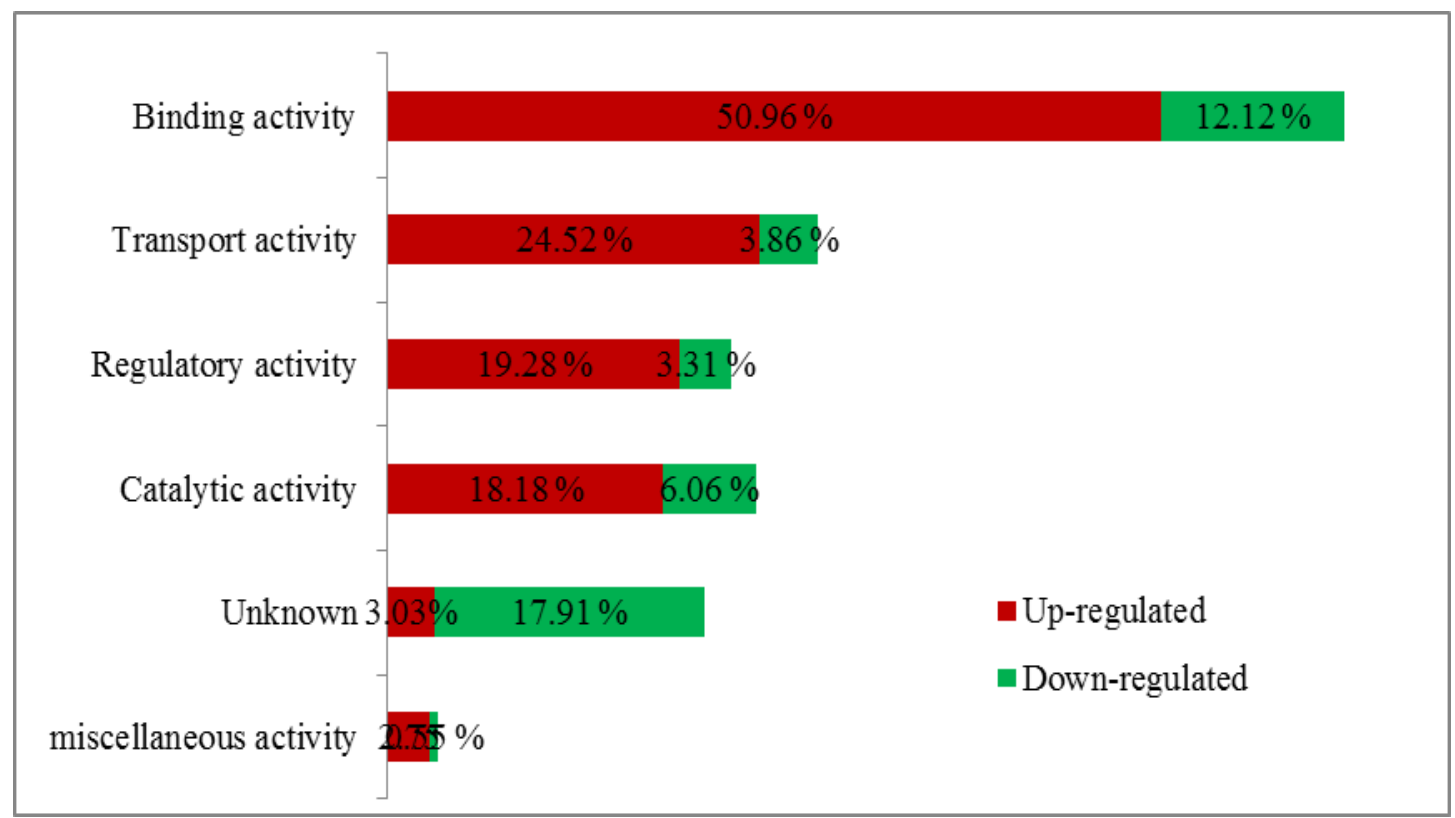

Figure 3b. The mouse liver cumulative chemical and pathogenic stress responding genes charaterization by Gene Ontology studies according to molecular function

\section{Characterization for biological processes}

The GO functional characterization of cumulative chemical and pathogenic stress responding genes for biological processes showed that $36.92 \%$ up-regulated and $11.84 \%$ down-regulated genes were engaged in regulation processes. The $40.77 \%$ upregulated and $6.89 \%$ down-regulated genes were involved in metabolism processes. The transport processes were performed by $30.30 \%$ up-regulated and $24.51 \%$ downregulated genes. The $23.41 \%$ up-regulated and $10.46 \%$ genes were engaged in development processes. The $27.55 \%$ upregulated and $3.58 \%$ down-regulated genes were showing response to stimulus processes. The signaling processes were showed by $15.14 \%$ up-regulated and6.06\% down-regulated genes. The $1.65 \%$ upregulated and $14.60 \%$ down-regulated genes were showing unknown processes (Figure $3 \mathrm{c})$. The results for function categorization through Gene-Ontology (GO) annotation are almost similar as Guruge et al, reported in 
rat liver under perflurooctanoic acid stress. Where the Gene Ontology biological processes revealed that most of genes were involved the metabolism, regulatory activity, development, signal transduction, transporter activity [19]. Similarly Thomas et al, reported almost the same results in studying mouse lungs and liver treated with different chemicals [8]. Cox et al, reported the same categories of biological processes in the analyzing gene expression of liver of baboons [21].

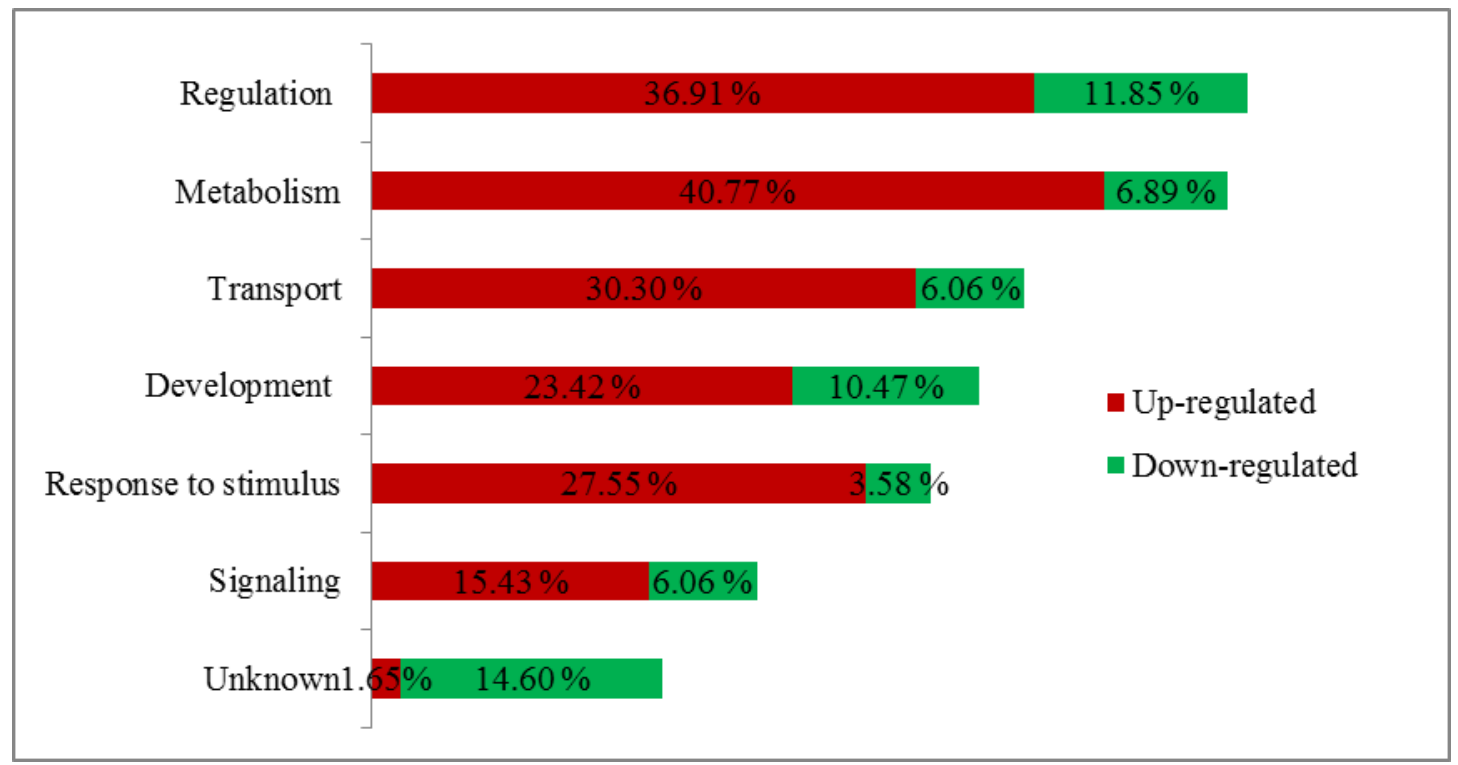

Figure 3c. The mouse liver cumulative chemical and pathogenic stress responding genes charaterization by gene ontology studies according to biological process

\section{Chromosome numbers}

The unknown number of chromosome for cumulative chemical and pathogenic stress responding genes was found to be $9.4 \%$ down regulation and $2.8 \%$ up-regulation. The $10.2 \%$ up-regulation and $2.2 \%$ downregulation genes were found to be on chromosome number 9 . The chromosome number 12 was found to be of $4.7 \%$ upregulation and $3.0 \%$ down regulation. The chromosome number 16 was found to be of $1.4 \%$ up-regulation and $0.0 \%$ on downregulation (Figure 3d). Most of genes profiled in this study were present on chromosome number 9 such Transferrin gene and Eukaryotic translation elongation factor 1 alpha 1 gene. Gene transferrin (Trf) was profiled on chromosome 9. Pausova et al, also profiled Trf gene on chromosome 9 of mouse but also on chromosome 8 of rat and chromosome 3 of human [22]. Similarly Newbery et al, profiled Eukaryotic translation elongation factor 1 alpha 1 (Eef1a1) gene on chromosome 9 of mouse but also on chromosome 6 of human [23]. Chromosomes 9, 12 and 16 have been used to study the disease linked with cancer by different researchers [24-26]. The different chromosome containing the same genes are known to be vastly homologous and to also show synteny conservation with chromosomes among organisms. 


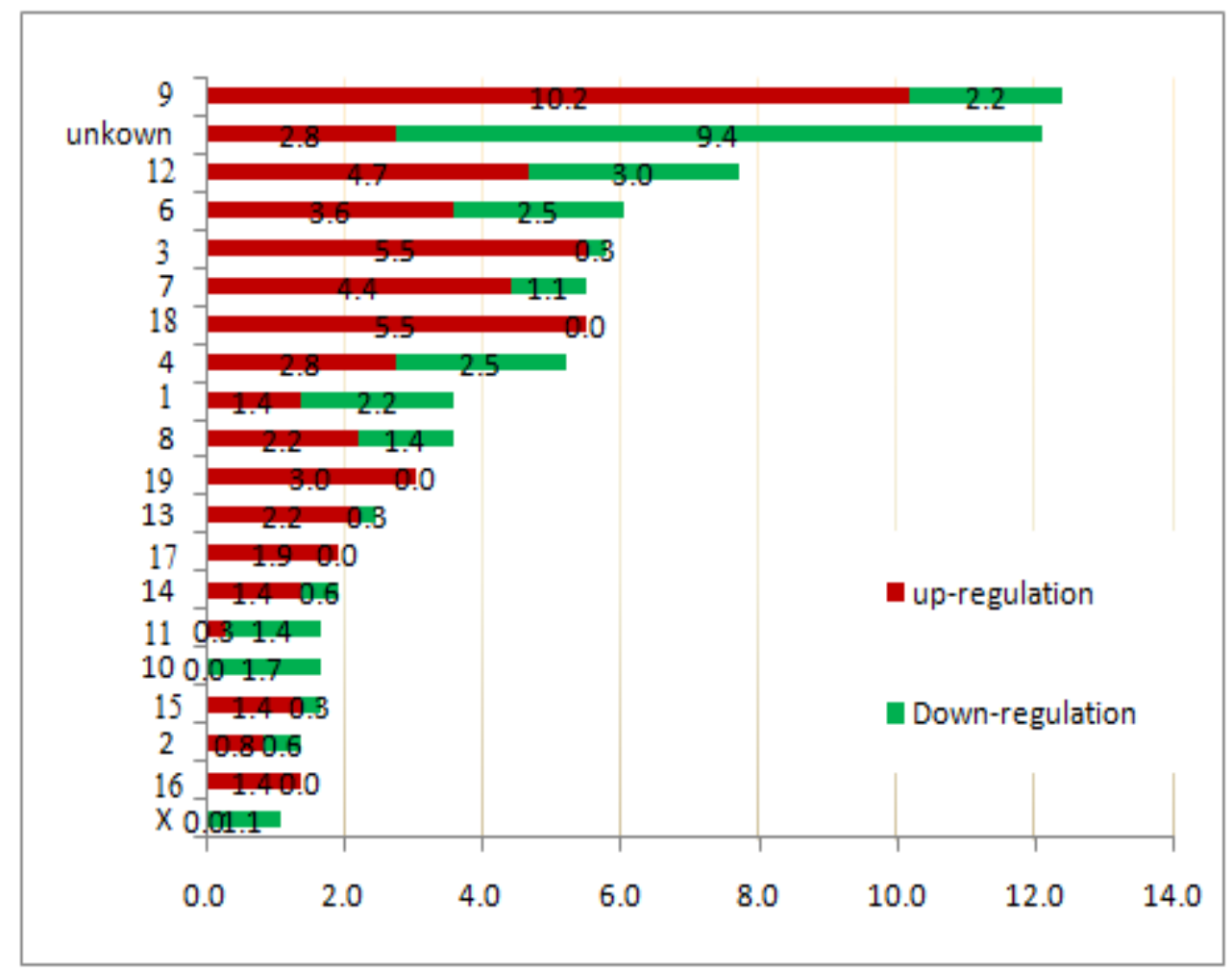

Figure 3d. The mouse liver cumulative chemical and pathogenic stress responding genes charaterization by UCSC genome browsre according to chromosome number

\section{Conclusion}

This analysis resulted of 363 cumulative chemical and pathogenic stress responding gene against at least three stresses among aromatic compounds, Perflurooctanoic sulphate, arsenic (as chemical stress) and Helicobacter hepiticus (as pathogenic stress). Computational analysis is an effective tool for the profiling and characterization of the genetic changes that are associated with chemical and pathogenic cumulative stress and is an applicable approach for discovering differentially expressed genes. This type of analysis will provide a precious source of information related with a gene responding program under chemical and pathogenic stresses.

\section{Authors' contributions}

Conceived and designed the experiments: MYK Barozai, Performed the experiments: F Behlil, Analyzed the data: F Behlil, Contributed reagents/ materials/ analysis tools: M Khan, F Bashir, S Muzaffar \& S Afzal, Wrote the paper: F Behlil \& Samiullah.

\section{References}

1. Musser GG \& Carleton MD (2005). Superfamily Muroidea. In: D. E. Wilson and D. A. Reeder (eds), Mammal Species of the World: a geographic and taxonomic reference, 894-1531. The John Hopkins University Press, Baltimore, USA.

2. Bedell MA, Largaespada DA, Jenkins NA \& Copeland NG (1997). Mouse models of human disease. Part II: recent progress and future directions. Genes and Development 11(1): 11-43.

3. Yang H, Zuo Y \& Fogo AB (2010). Models of chronic kidney disease. National Institutes of Health 7(1-2): 1319.

4. Flahou B, Haesebrouck F, Pasmans F, D’Herde K, Driessen A \& Van-Deun, 
$\mathrm{K}$, et al (2010). Helicobacter suis causes severe gastric pathology in mouse and Mongolian gerbil models of human disease. PLOS One 5(11): e14083.

5. Rosen MB, Schmid JR, Corton JC, Zeh RD, Das KP, Abbott BD \& Lau C (2010). Gene Expression Profiling in Wild-Type and PPAR $\alpha$-Null Mice Exposed to Perfluorooctane Sulfonate Reveals PPAR $\alpha$-Independent Effects. PPAR Research 794739.

6. Nordstrom DK (2002). Public health,Worldwide occurrences of arsenic in ground water. Science 296: 2143-45.

7. Ponzetto A, Pellicano R, Leone N, Cutufia MA, Turrini F \& Grigioni WF et al. (2000). Helicobacter infection and cirrhosis in hepatitis $\mathrm{C}$ virus carriage: is it an innocent bystander or a troublemaker? Medical Hypotheses 54(2): 275-277.

8. Thomas SR, O'Connell MT, Pluta L, Wolfinger DR, Yang L \& Page JT (2007). A Comparison of Transcriptomic and Metabonomic Technologies for Identifying Biomarkers Predictive of Two-Year Rodent Cancer Bioassays. Toxicol Sci 96(1): 40-46.

9. Kawamoto K, Sato I, Tsuda S, Yoshida M, Yaegashi K \& Saito N, et al. (2011) Ultrasonic-induced tonic convulsion in rats after subchronic exposure to perfluorooctane sulfonate (PFOS) $J$. of Toxicol Sci 36(1): 55-62.

10. Lu T, Liu J, Lecluyse EL, Zhou YS, Cheng ML \& Waalkes MP (2001) Application of cDNA microarray to the study of arsenic-induced liver diseases in the population of Guizhou. China. Toxicol Sci 59: 185-92.

11. Lui J, Xue L, Guang L, Hong W, Dong L \& Jian J et al. (2008) In-silico analysis and verification of S100 gene expression in gastric cancer. $B M C$ Cancer 8: 261.

12. Barozai, MYK \& Wahid HA (2012). Insilico identification and characterization of cumulative abiotic stress responding gene in potato (Solanum tuberosum L). Pak J bot 44: 57-69.

13. Barrett $\mathrm{T}$, Troup DB, Wilhite SE, Ledoux P, Evangelista C \& Kim IF, et al. (2011). NCBI GEO: archive for functional genomics data sets-10 years on. Nucleic Acids Res 39: 1005-1010.

14. Lomax J (2005). Get ready to GO! A biologist's guide to the Gene Ontology. Brief Bioinform 6: 298-304.

15. Sioson AA, Mane SP, Li P, Sha W, Health LS, Bohnert HJ \& Grene R (2006). The statistics of identifying differentially expressed genes in Expresso and TM4: a comparison. BMC Bioinform 7: 215-230.

16. Saeed AI, Bhagabati NK, Braisted JC, Liang W, Sharov V \& Howe EA, et al. (2006). TM4 microarray software suite. Methods enzymol 411: 134-193.

17. Aporntewan $\mathrm{C} \&$ Mutirangura A (2011). Connection up and down regulation expression analysis of microarrays (CU-DREAM): a physiogenomic discovery tool. Asian Biomed 5: 257-262.

18. Fox JG, Feng Y, Theve EJ, Raczynski AR, Fiala JL \& Doernte AL, et al. (2010). Gut microbes define liver cancer risk in mice exposed to chemicaland viral transgenic hepatocarcinogens. Gut 59(1): 88-97.

19. Guruge SK, Yeung YWL, Yamanaka N, Miyazaki S, Lam SKP \& Gisey PJ, et al. (2006). Gene Expression Profiles in Rat Liver Treated With Perfluorooctanoic Acid (PFOA). Toxicol sci 89(1): 93-107.

20. Hazbun TR, Malmstrom L, Anderson S, Graczyk BJ, Fox B \& Riffle $M$ et al. 
(2003). Assigning Function to Yeast Proteins by Integration of Technologies. Molecular Cell 12: 13531365.

21. Cox LA, Schlabritz-Loutesevitch N, Hubbard GB, Nijland MJ, Mcdonald TJ \& Nathanielsz PW (2006). Gene expression profile differences in left and right liver lobes from mid-gestation fetal baboons: a cautionary tale. $J$ physiol 572 (1): 59-66.

22. Pausova Z, Bourdon J, Clayton D, Mattei MG, Seldin MF \& Janicic N, et al. (1994). Cloning of a parathyroid hormone/parathyroid hormone-related peptide receptor (PTHR) c DNA from a rat osteosarcoma (UMR 106) cell line: chromosomal assignment of gene in human, mouse and rat genomes. Genomics 20(1): 20-26.

23. Newbery HJ, Loh DH, O'Donoghue JE, Tomlinson VAL, Chau YY \& Boyd JA et al. (2007). Translation elongation factor eEF1A2 is essential for post weaning survival in mice. $J$ Biol Chem 282(39): 28951-28959.

24. Humphray SJ, Oliver K, Hunt AR, Plumb RW, Loveland JE, Howe KL, Andrews TD, Searle S, Hunt SE, Scott CE \& Jones MC (2004). DNA sequence and analysis of human chromosome 9. Nature 429(6990): 369-74.

25. Scherer SE, Muzny DM, Buhay CJ, Chen R, Cree A, Ding Y, Dugan-Rocha S, Gill R, Gunaratne P, Harris RA \& Hawes AC (2006). The finished DNA sequence of human chromosome 12 . Nature 440(7082): 346-51.

26. Rakha EA, Green AR, Powe DG, Roylance R \& Ellis IO (2006). Chromosome 16 tumor-suppressor genes in breast cancer. Genes, Chromosomes and Cancer 45(6): 52735. 